\title{
Solid/Multicystic Ameloblastoma
}

National Cancer Institute

\section{Source}

National Cancer Institute. Solid/Multicystic Ameloblastoma. NCI Thesaurus. Code C39755.

An intraosseous ameloblastoma that arises from the jaw, usually the mandible. It grows slowly, invades locally, and recurs frequently. It presents with swelling of the jaw. 